\title{
Documentary subjects speak out: Relational empathy and ethics in intercultural documentary film education
}

\author{
Jan Nåls* - Arcada University of Applied Sciences and University of Helsinki, \\ Finland
}

\begin{abstract}
The teaching of documentary film faces particular ethical and practical challenges in intercultural environments when working with marginalized groups. The author of the paper was one of the acting teachers for an intercultural group of film students making documentaries on sex workers in rural South African communities in 2015. The paper explores the pedagogical and ethical dimension of the encounters between students and the documentary subjects. It argues for the benefits of creating shared meaning - a third culture - through the fostering of relational empathy between student film-makers and their subjects. The focus of the analysis lies in the emotional reactions of the documentary subjects, observed in community screenings in 2016. Conclusions suggest that the concept of relational empathy can help us understand and develop the teaching of documentary in novel ways. It represents a pedagogical choice that is ethical, as it allows for consent that is truly informed.
\end{abstract}

Keywords: documentary film; education; intercultural communication; representation; relational empathy; ethics

\section{Introduction}

Film-making does not occur in a cultural vacuum, nor does film education. Documentary film-makers, in particular, are frequently faced with the task of representing individuals who are considerably different in terms of their cultural background, ethnicity, social class and their experiences of privilege, cultural agency and so forth. The teaching of documentary film-making, by default, entails multiple ethical and practical challenges that are magnified when representing - and interacting with - marginalized groups.

In spring 2015, I acted as one of the supervisors for an intercultural group of third-year film university students from Africa and Europe. The students were making documentaries on sex workers in rural South African communities, as part of a six-month documentary programme, Cornered Voices, within the framework of an international exchange programme called Documentary and Diversity (Hyde-Clarke, 2014).

This study addresses the interaction between film students and their subjects, the sex workers, during the documentary film process. I knowingly use the word 'subject' when referring to the community members who participated in the documentary films. The word is a reminder of the imbalance of power that exists in much of documentary film production. The analysis focuses on the three separate screenings of the finished documentaries that were organized for the documentary subjects in their respective local communities. The screenings took place in March 2016, almost a year after the 
shoot. The responses of the subjects highlight an often overlooked aspect of the teaching of documentary film-making - the complex relationship between film-maker and subjects, and the experience of the latter. In this study, the documentary subjects are given an opportunity to speak out.

The documentary film process under examination is treated as an example of intercultural communication. The students who took part in Cornered Voices represented three nationalities - South African, Ghanaian and Finnish - and came from various social, ethnic and cultural backgrounds. None of the students had roots in the rural communities in which the films were made, and the life situations of the sex workers were strikingly different from those of the film students, who were very privileged by comparison. The students formed intercultural film production teams that were asked to produce short documentaries on the topic of sex work in rural South Africa. Apart from the educational institutions, there was an additional stakeholder that influenced the process - Re-Action! - a social entrepreneurship that was invited to join the process as a provider of knowledge and access to the marginalized communities. From the beginning, it was agreed that they should not act as a commissioner of the films, nor should they influence the chosen stories, or how they would be told. The focus was to be firmly on the relationship between film students and their subjects, which Re-Action! would enable.

To understand the process anew, I employ the concept of relational empathy as the central theoretical approach of this study. Empathy is a broad concept that is considered central to human experience. As Edith Stein (1989: 60) argues, empathy is 'the basis of intersubjective experience' and 'the condition of possible knowledge of the existing outer world'. Amy Coplan defines empathy as 'A complex, cognitive and affective, imaginative process, in which the observer simulates another person's situated psychological states while maintaining a clear other-self differentiation' (Coplan and Goldie, 2011: 5). The concept of empathy has received much attention in the study of literature and film (Keen, 2006; Gaut, 2010; Tan, 2011; Currie, 1995), but also in other areas, such as in the study of intercultural communication and education. A relational view of empathy is advocated in the teaching of intercultural communication by, among others, Benjamin J. Broome (1991), with an emphasis on a productive, rather than a reproductive, approach to understanding. Relational empathy de-emphasizes similarity between the communicators, concentrating instead on the development of a 'third culture', thus providing a possibility to create shared meaning in pedagogic settings (Broome 1991: 235). Broome's approach is in line with a paradigm shift in documentary film-making ethics, advocated by Sanders (2013). Sanders proposes that the role of a subject can be that of a co-creator, committed and involved in the filmmaking process. This relationship includes facilitating the exchange of information, questions and concerns, as well as the building of trust to negotiate and guard the interests of all parties (ibid.). A collaborative view of documentary film practice and education can entail relational empathy, in a relationship in which film-maker and subject are able to understand each other through empathy, and thus go on to create new meanings together.

A principal aim of this study is to explore the pedagogical and ethical dimension of the encounters between the film students and the subjects with the help of these theoretical concepts. Another aim is to allow for individual voices to be heard, and I focus the analysis in particular on the emotional reactions and verbal responses of the subjects during the three screenings.

A further aim of this study is to render the process of education visible. Often, teachers, supervisors and students lack sufficient time to reflect upon the process of 
teaching and learning taking place during intense periods of film production. When such processes are discussed, they are often related to film-making and the learning process of the students. The discussion seldom involves other parties, such as the documentary subjects, as I will attempt to do here. The material featured in this essay consists of observations and written notes from the process of delivering the project and the three subsequent feedback sessions when the subjects were able to view the films.

The structure of the study mirrors the intertwining processes of learning and documentary film production. First, I map out the theoretical and practical challenges before production, and some of the proposed solutions. I proceed to describe the overall ethos of the productions and the production process that ensued, followed by an account and analysis of the responses of the documentary subjects. Lastly, I will offer conclusions on this study, as well as some suggestions for the teaching of documentary film in intercultural settings.

\section{Challenges of documentary film education}

Student documentary film-makers learn their trade working with real people in unscripted situations, and educators have a responsibility in this respect to guide their students towards an ethically informed position to minimize harmful effects. Bill Nichols (2001: 9-10) contends that ethics exist to govern the conduct of groups regarding matters for which hard and fast rules, or laws, will not suffice. Legal frameworks alone are too loose to compel - or even encourage - ethical practice in documentary film-making. Thus, it is the responsibility of each different film-maker who participates in a documentary process to be conscious of the ethics involved. Ethics in the documentary context measure how the relationship between film-maker and subject has consequences for the subjects themselves, as well as the subsequent viewers of the film. As recent studies show, however, ethical guidelines for documentary film production and in film and media education are conflicted and challenged, even among film-makers and educators themselves (cf. Aufderheide et al., 2009; Nash, 2009; Ruby, 2005). There is no clear set of ethical rules, and film-makers (including students) and subjects alike must often deal with ethical choices on the fly.

The key to ethical film-making, as Brian Winston (1995: 240) argues, lies in the attitude and sensitivity of the film-maker to the subject, and the intimate relationship they establish, of which the documentary film is a tangible outcome. The covenant between the two parties tends to come under different kinds of strain. The documentary process can be ripe with tensions, misunderstandings and differing intentions. This is typically magnified in film education, where the film-makers are inexperienced and other stakeholders - namely, the educating institutions and their representatives - influence the process. The task for the students who took part in Cornered Voices provided the additional challenge of working in intercultural teams, each member coming from a different cultural background. The rural locations presented students coming mostly from urban backgrounds with significant practical challenges, as well as cultural ones. In the following discussion, I examine the context of the subsequent student documentary productions by looking at the ethical and practical challenges involved in the planning of Cornered Voices. Some of these apply exclusively to film education, others to documentary film-making in a more general sense.

The first, and perhaps most formidable, challenge was the imbalance of power inherent in documentary film production. Student documentaries - as well as 
documentaries in general - present an ethical problem in how to position the subjects as equal to the film-maker, and subsequently to the viewer. A crucial dimension in this complex phenomenon is how to secure the agency of those involved. By agency, I mean the capacity of an individual to commit to moral, ethical, legal and other forms of obligations towards fellow human beings. Documentary subjects are often disempowered, as they lack control and understanding of the overall narrative and the different facets of production (cf. Aufderheide, 2009; Nash, 2012; Sanders, 2013).

A second aspect affecting the ethics of our production process was the double nature of documentary film, that is, the fact that it can be understood either as an artefact - text - or as a communicative process. If perceived as a text, the subjects can be treated as characters - dramatis personae - in a manner similar to the creation of characters in fiction film. If so, the agency resides with the film-maker, who uses the personal traits and lives of the subjects for purposes defined predominantly by the film-maker. Any ethical considerations will in this case primarily concern the filmmaker's relationship to the audience, and only in a secondary sense to the subjects. However, if the documentary is understood as communication, as a chain of human interaction, then the texture of ethical considerations becomes more intricate, as it means that there are at least three positions involved within the process: the filmmaker, the subjects and the viewers. If each of these positions is considered equal, they should have the same possibilities to commit and to engage in relation to one another.

Third, in projects such as Cornered Voices, student film-makers often experience conflicting obligations during their production process: to themselves, their student colleagues, their subjects, sponsors or other stakeholders, lecturers, and their potential audience. In this contested environment, it may prove difficult for an inexperienced film-maker to maintain focus on the obligation to his or her subject. Conflicting commitments also affect the subjects, as they are busy with their lives while they are also participating in a production process that is often hectic and demanding. The film-maker and subject often enter a production process with different backgrounds in terms of culture, ethnicity, class and so forth. This gap may lead to misunderstanding and miscommunication. Intentions and value hierarchies between film-maker and subject can thus be entirely out of sync.

Considering the above, the teaching of documentary film-making can be challenging terrain for students and their subjects. The teaching staff on Cornered Voices thus felt a need to create critical moments in the communicative process that could allow the subjects of the films a degree of agency. To achieve this, the planning parties held different planning meetings before and during production. In the following, I will map out the historical and pedagogical context for the case study, and recount the process that followed.

\section{The process of documentary film education}

In 2006, an intercultural exchange programme was established between higher education institutions in Finland and South Africa. In the following ten years of its existence, the programme and its expanding network of institutions used documentary film as a method of enquiry into questions of intercultural understanding, as well as a practical outcome of that enquiry. The exchange programme was initially called Training Producers for Ecological Broadcasting; it was later renamed Documentary and Diversity. It was part of the North-South-South Exchange (NSSE), a funding instrument devised by the Ministry of Education and Culture in Finland aimed at enhancing cultural 
understanding and building academic networks between Africa and Europe. Each year, the programme decided on a common theme that informed the lectures and the productions. The institutions in 2015 included the University of Helsinki (Finland), Arcada University of Applied Sciences (Finland), AFDA (South Africa), the University of Witwatersrand (South Africa) and NAFTI (Ghana).

From the outset, all members of the network acknowledged the value of culturally sustainable and socio-economically viable media production, particularly documentary film-making, in a global media market dominated by transnational corporations and Anglo-American aesthetics. Finnish, as well as South and West African, media producers and media educators, struggle to launch productions and other modes of expression that serve the cultural, social and political needs of local communities (Hyde-Clarke, 2014). The so-called gaze of the Western producer tends to infiltrate production processes, even if they are carried out by local people (Shohat and Stam, 1994: 181-3). In 2015, the overarching theme of the Documentary and Diversity exchange programme was named Cornered Voices by staff from the institutions. It was a theme that sought to encourage participants to engage with marginalized groups lacking a voice in society, with a particular focus on gender issues and the representation of sex work in media. To achieve this goal, the network institutions partnered with Re-Action!, a social entrepreneurship based in Johannesburg in South Africa. Re-Action! focuses on social issues, such as access to medicine and prevention of sexually transmitted diseases in the mining industry, in South Africa and its neighbouring countries. Through the collaboration, the network gained access to, and knowledge of, the world of sex workers in rural South Africa. Re-Action! had an impact on the process in multiple ways, especially in selecting the subjects for each film, but in this study, the focus is on the relationship between student film-makers and their subjects.

The process for the Cornered Voices project started with meetings between faculty and staff from Re-Action! Neither students nor potential subjects were present in these introductory planning meetings. From the start, it was decided that the films were to be used by Re-Action! to empower women in Africa and beyond, as well as to fight misconceptions and prejudice concerning sex work, women and health. The overall process was designed to be an ongoing dialogue in which the first phase of the production process was to be a research trip by the student film-makers, facilitated by Re-Action! The trip was preceded by a session where Re-Action! briefed the students on various aspects of sex work in South Africa. The students were also asked to identify their prejudices against sex work. The research trip marked the first time that students met with the members of community and potential subjects. The second phase involved the actual shooting of the films, which took place in Lydenburg, Klerksdorp and Nelspruit in the northern parts of South Africa in early 2015. The third phase of the process was the post-production, which resulted in finished films articulating the filmmakers' view of the events and the subjects they had encountered. The programme produced three short documentary films: Threads (2015), in which sex workers speak of their first sexual experiences, as well as their first contacts with sex work; Loveable (2015), which tells a story of Thandeka Mokoena, a former sex worker who seeks change for her and her young son (see Figure 1); and Forbidden Fruit (2015), which follows the lives of several sex workers in order to study how prostitution affects the community of Nelspruit (see Figure 2). 


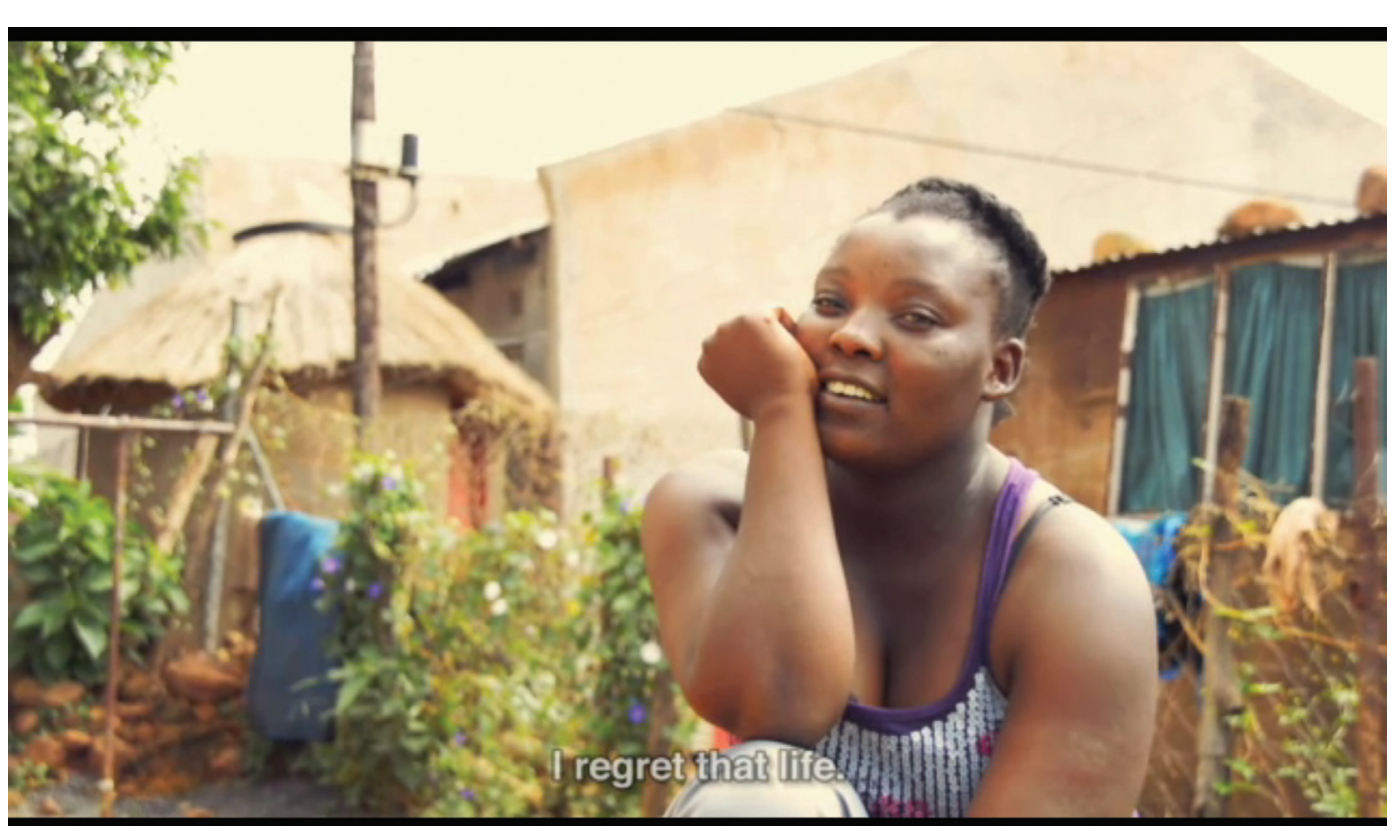

Figure 1: Thandeka Mokoena, a former sex worker from Klerksdorp, is seeking a new life for her and her young son (still from the short documentary Loveable, 2015)

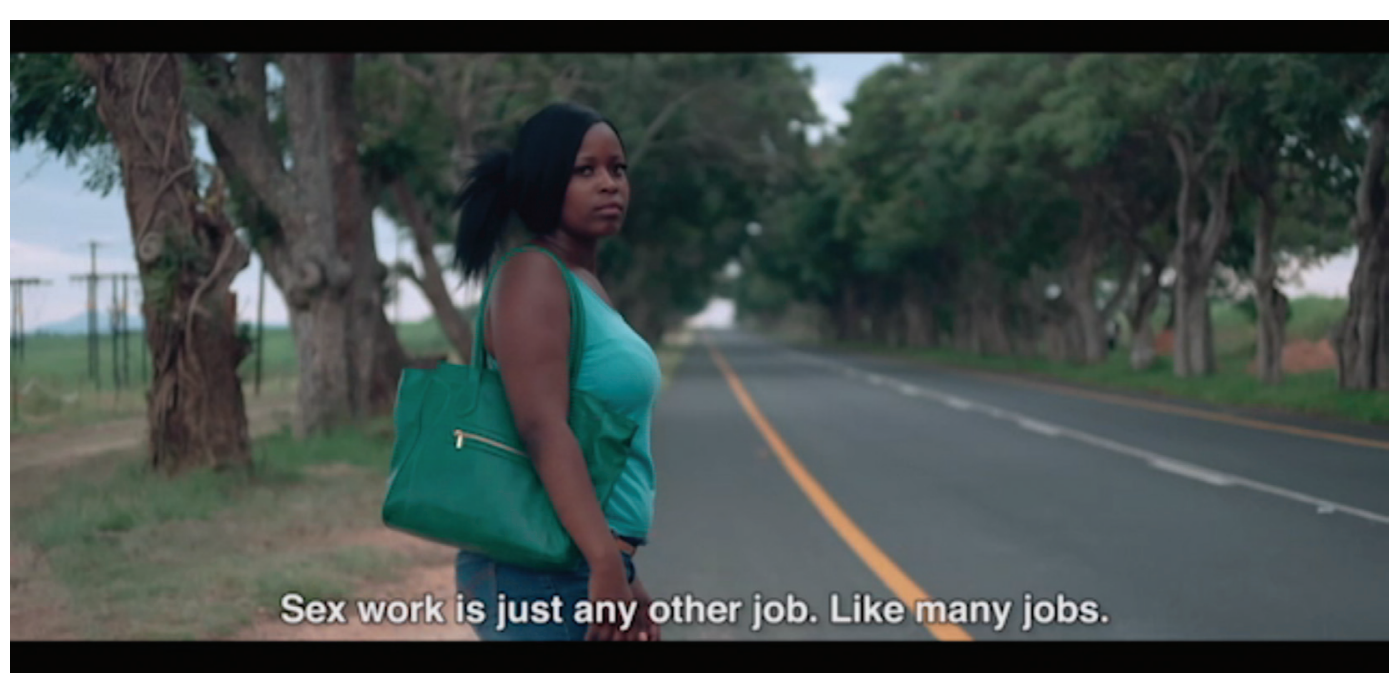

Figure 2: A sex worker in Nelspruit is looking for customers while she reflects on the nature of her work (still from the short documentary Forbidden Fruit, 2015)

The fourth and concluding phase of the project consisted of 'talk-back' sessions with the subjects, together with their communities. A group of students and teachers, as well as staff from Re-Action!, revisited the shooting locations on 10 March 2016 to join a special screening to which all subjects who had participated in the production process were invited. It was this final phase that informed this study.

As a pedagogical endeavour, Cornered Voices was in many ways an example of 'collaborative pedagogy' (Lassiter and Campbell, 2010: 370-1), where students, faculty and community participants were engaged as teachers and learners throughout the project (see also Austin and Moore Quinn, 2007; Nocon et al., 2004). The faculty members were not the only instructors: students were teaching Re-Action! staff and 
community members about the practical challenges of documentary film-making on such a sensitive topic; Re-Action! staff and community members were informing students and faculty members about the realities of sex work and how to act respectfully and responsibly in local communities; and faculty members were teaching students, the personnel of Re-Action! and the community members about how documentary film can be used to raise awareness on topics such as sex work.

\section{Relational empathy as a framework}

How can we best understand and analyse the experience of students and subjects on a project such as Cornered Voices? A standard practice in proximate research is to focus on the films, as they are the most tangible outcomes. This end product is often the focus in teaching as well: as film teachers, we teach (among other similar and related topics) storytelling, shot composition and interview techniques - skills designed to enhance the end product of a film-making process. That end product also tends to be the object of assessment at the end of production courses such as Cornered Voices. Another, distinctly different approach to understanding the experience of diverse participants in a project such as Cornered Voices is to focus on the relationships between various stakeholders. Relational empathy is a useful concept in this regard.

Most scholars (cf. Coplan, 2004; Keen, 2006; Gaut, 2010; Tan, 2011; Vaage, 2010) associate empathy with the attempt to consider the perspective of another person. This then has significant ethical implications, for empathy arguably has the potential to communicate new feelings, and to break down prejudices and stereotypes by creating emotional connections between others (cf. Keen, 2006; Thomson-Jones, 2008).

However, there has arguably been an overemphasis on similarity when defining empathy. Katz (1963: 6-7), for example, suggests that 'we tend to empathize with those who are familiar to us or whose life situation is most similar to our own'. From such accounts, it may seem hard, or even impossible, to experience empathy when encountering those who are very different from ourselves. A relational view of empathy overcomes the need for similarity and many of the difficulties associated with intercultural empathy. This approach suggests a 'productive rather than a reproductive' approach to understanding - and the sense of pursuing a shared meaning (Broome, 1991: 240). Thus, understanding is not viewed as a product that is final. We do not find out conclusively what the other is thinking and feeling, nor do we uncover hidden emotional states. Instead, we create understanding together through relational empathy, in an ongoing process occurring between communicators.

This approach allows student film-makers to acknowledge that their task is not merely to reproduce the other's meaning but to be open to the meanings that are being developed between themselves and the other. The produced meanings interculturalists use the term 'third culture' (Casmir and Asuncion-Lande 1989: 294) are then articulated and made partly visible in the finished film.

In my experience as an educator, this notion differs somewhat from the two usual positions of student film-makers in relation to their documentary subjects. Many documentary film students adopt a position as auteurs, viewing subjects and their lives effectively as 'material' from which they can construct an engaging narrative. This attitude may, in part, be due to the general dominance of fiction in film schools and their curricula. Students adopt the identity of an auteur and tend to focus on product rather than process. The process, then, is simply a means through which to accentuate the understanding and artistic vision of the individual student film-maker. The second position is what I call the position of the journalist, in which the student film-maker 
stresses fair and proper representation of the subjects, which they perhaps understand as 'giving voice' to those who do not have one, as in Cornered Voices. Inexperienced student film-makers tend to favour this position, as it seemingly relieves them of some of the responsibilities and pressures always present in film production. The latter position is often favoured in sensitive situations, such as in our case study when dealing with sex workers, or dealing with other marginalized groups, as it supposedly allows the film students to address the imbalance of power between film-maker and subject.

Although both the described positions are simplified, they are, nonetheless, present in documentary film education. As previously stated, however, I advocate for a third position that prioritizes a sense of relational empathy and shared meaning arising from the meeting between film-maker and subject. Relational empathy is particularly important when the difference between the communicators is as significant as it was between the participants in Cornered Voices. The development of such understanding also arguably reduces the dependency upon the skills of the film-maker, as the interpretation involves both participants. At the same time, such an approach could also be seen to empower the student film-makers to take an active and responsible role in the meaning-making process.

Relational empathy would thus seem a powerful model when pursuing understanding in intercultural communication - in theory, at least. In the following discussion, I will look at the practical implications in examining what the reactions of the subjects reveal about the communication and relation between film-maker and subjects. As the production process was designed to be an ongoing dialogue, it had the potential to create relational empathy, and thus to create a sense of understanding across cultural, as well as other, divides. The following analysis of the subjects' responses gives an indication of whether the attempt to foster a sense of shared understanding was successful.

\section{The subjects speak out}

In March 2016, the three short documentary films from the Cornered Voices project - Threads (2015), Loveable (2015) and Forbidden Fruit (2015) - were screened in Lydenburg, Klerksdorp and Nelspruit in the northern parts of South Africa where they were shot. The screenings were open to the local communities, including the actual subjects of the documentaries, who were considered the primary audiences for the screenings. All three films were screened at each of the locations.

The screenings were held at local community centres in which the audiences consisted of approximately 15-20 sexworkers, their friends and families, alongside other community members from the municipality and health departments. In Lydenburg, the screening was delayed for over an hour because the sex workers had trouble arranging transport to the venue. Afterwards, it was revealed that their driver had been in a car accident, partly because there was only one car available for over 20 people, and the driver was in a hurry. Fortunately, he was not badly hurt, but such an anecdote gives an example of the practical difficulties in arranging sessions where film-makers and subjects meet after a production, especially when the subjects are part of marginalized communities in distant locations. The quotations in the following section are pertinent parts of the dialogue between the sex workers (SW 1-6) and student film-makers (SF 1-5), and are taken from the three separate screenings on 10 March 2016 in Nelspruit, Klerksdorp and Lydenburg in South Africa. The events were observed on location, and discussions were written down verbatim at the three events. 
While observing the subjects' initial reactions and responses, it became clear that there was a sense of bewilderment and confusion, and subsequently many open questions:

- 'What are we doing here?' (SW1)

- 'Why are you showing these films to us?' (SW2)

- 'What is happening now?' (SW3)

Despite many previous detailed meetings between the film-makers and subjects, the initial impression at the screenings was one of confusion, particularly among the subjects. This clearly indicates a lack of understanding, as well as a lack of a common, or third, culture, as advocated by Broome (1991) and Casmir and Asuncion-Lande (1989). A sense of common purpose was missing, as the subjects seemed to be at odds as to the nature of the event, and also questioned their presence at the screenings. It had been almost a year since the shoot and since they had last met with the filmmakers. Practical and financial limitations had made frequent communication between student film-makers and subjects impossible. Many of the student film-makers had returned to their homes elsewhere in South Africa, Finland and Ghana after the shoot, and the subjects did not have regular access to devices that would allow for overseas communication, nor did they have regular access to the internet. At the screenings, the student film-makers acted as hosts, and they explained the rationale and ethos of the screenings:

- 'We promised you we would show them.' (SF1)

- 'Out of respect, we wanted to come back.' (SF2)

- 'We wanted to show that change is possible.' (SF3)

Two distinct reactions became visible when the screening started, and the subjects saw themselves projected on a big screen: one was silent, concentrated viewing with occasional comments and shouts when spectators recognized familiar spaces, characters and events on screen:

- 'Legalize it.' (SW2)

- 'Yes, yes, it's true.' (SW4)

The first comment refers to the fact that prostitution is illegal in South Africa.

The other dominant reaction during viewing was one of shock and dismay. The main character of Loveable, for example, Thandeka Mokoena, watched the film for a couple of minutes, and then got up and left. She came back, but left again shortly thereafter, before coming back once again. The screening marked the first time she saw the entire finished film. Another main character, upon seeing herself on the screen, shouted loudly:

- 'I hate!' (SW3)

Another responded:

- 'I hate men.' (SW4)

After the three films, discussions were held that focused upon the feelings and thoughts initiated by the films. The discussions, moderated by the students, were lengthy and touched on different subject areas. Many topics were not connected to the documentary films or their production process at all, but rather to issues raised in the films, and to the ongoing lives of the characters:

- 'We could do with a lawyer helping us with the police [harassment].' (SW5) 
- 'What about those you interviewed but were not there [in the film]?' (SW2)

- 'Unfortunately we will not get [medical and financial] support in the future ... for our community, it is a question mark - what next?' (SW2)

The limited power of film-making became evident from these comments and similar longer discussions. As one of the subjects phrased it: 'Yes, documentary can be educational, but it doesn't protect us.' The experience of watching the films in a public setting also made the subjects acutely aware of - but perhaps also gave them the courage to speak of - the different hardships of their lives. Immediately after the screenings, the subjects commented more on their safety and their uncertain futures than on the actual films or the process behind them. The students tried to steer the discussion to the films, and to the process behind them, but this proved difficult.

The screenings also awoke new ambitions. One student wanted to 'learn more' (SF2). A subject comment also spoke to a change of perspective: 'if it can be seen by many ... people might change [their attitudes]' (SW2). Both comments indicate that change had taken place. The student was no longer focused on product but on an ongoing learning process. The subject, on the other hand, was no longer solely focused on her individual situation, but in creating change in the attitudes of others. An almost identical comment was made at another screening: 'I wish it can be seen by a lot of people that they can learn to better their lives' (SW5).

As the discussion evolved, the subjects did offer varying perspectives on the films. Many comments dealt with the emotional impact of the films:

- 'It is emotional ... not so educational.' (SW5)

- 'It breaks your heart. Most of us have stories that ... [voice trails off].' (SW1)

- 'You did good ... It is overwhelming, in fact.' (SW4)

The student film-makers responded in turn:

- 'We try to show hope and to break down prejudice and stereotypes regarding sex workers. Who are we to judge? It was good to come here and take part in your lives, and share the human spirit.' (SF2)

- 'We wanted to show the human side, to tell something that is truthful, but also to tell a good story. It is a constant battle.' (SF1)

At the end of the talk, one of the subjects stepped into the role of a teacher, and even suggested an assessment. Another subject gave a statement that offered a glimpse of the individual impact of taking part in the documentary film production process:

- 'If I were a teacher, I would give a mark of 98 per cent out of 100 per cent ... the 2 per cent I won't tell you why.' (SW1)

- 'I am not that person anymore.' (SW5)

Although many of the subjects felt visibly uncomfortable during the start of the screening and were also uncertain of the purpose of the films, most became increasingly engaged while watching the films. During viewing, the subjects talked at the screen, responding with vocal shouts to events and characters. Afterwards, many testified that they had been empowered by the process - by the fact that somebody had made an effort to understand them. They also mentioned that they did not feel pitied. Similar comments indicate that the communication process is very much perceived as a oneway street, by film-makers and subjects alike. After watching herself, the main character of Loveable spoke of how she saw herself in a new light:

- 'I am a different person now [pointing to the now empty screen]. It changed me.' (SW2) 
Change was a theme to which all parties - students, subjects and lecturers - referred. Everybody sought change, although change meant different things to different people. Students spoke of attitude change in themselves and potential audiences, whereas lecturers advocated change in the students' mindset and skills. The subjects were preoccupied with seeking change in their often-tough life situations. Interestingly enough, some of these viewpoints started to merge as the discussions after the screenings evolved. The screenings provided an opportunity to articulate change, and to create shared understanding - and perhaps agree on some common goals - through, I would argue, relational empathy (Broome, 1991).

\section{Conclusions and recommendations}

As an initial conclusion, this study would seem to suggest that the participating filmmakers and subjects did not develop relational empathy in their interaction during the production, since a common understanding of purpose was partly missing. As one subject asked: 'What are we doing here?' (SW1). This lack of common understanding has an ethical dimension, too, since informed consent is intimately tied to subjects' understanding of function, genre and the future context(s) of the documentary film in which they are taking part. An intimate first viewing, in which only the main subjects would have been present, would have been preferred. This would arguably have eased the shock of viewing oneself on screen for the first time, especially if the viewing is a public event with others present, as was the case in Cornered Voices. Intimate screenings would also have allowed for questions in a safer, more private space than a public screening allows. Such a viewing was not deemed possible due to financial and practical constraints.

Another source of confusion was in regard to the function of the films. The design of the screening added to the bewilderment, as local dignitaries were present, and many of them expected 'educational' films, whereas the films exhibited were what many comments labelled 'emotional' films. Because of this mixed constitution and expectations of the spectators present, the experience of watching the films did not meet the subjects' expectations, at least at first. Perhaps this was evident also in the manner in which the screenings were set up. It was the film students - supported by the educational institutions and Re-Action! - who showed the films to the subjects and their communities, and this therefore constructed a passive, receiving role for the subjects. Power hierarchies inherent in the production process were thus reinforced in the screening. It would have been very different, as one student suggested in later discussions, if the subjects had presented the films to the audience together with the film-making students. The discussion about the educational and emotional impact of the films was helpful, however, since it allowed the students to talk directly with their subjects about possible readings and impacts of the films. Overall, another conclusion drawn from the screenings was that a common language of talking about film and the process behind it was missing. During their studies, film students are introduced to terms such as 'emotional impact', 'break down prejudice' and 'give voice', and also to other terms more related to the practical side of production, such as 'documentary', 'narrative', 'structure' and 'open ending'. These and similar words associated with film practice were used many times during the screenings. To the subjects, however, these words and phrases were not fully intelligible and thus had limited relevance. What did 'give voice' really mean for the subjects? The students, as well as the lecturers, found that 'voice' might be a useful theoretical concept, but one that was hard to define in practice. 
The screenings provided a moment of revelation for many of the students, who, coming into the screenings, were still very much focused on their end products, and felt that the process had ended, or at least that it would end at the screenings. Once at the screenings, the student film-makers got a stark reminder that the lives of the films' subjects continue, as does the documentary film process itself. When asked about how to improve living and working conditions through the making of documentaries, one of the student film-makers responded: 'I do not have answers.' This answer struck me as a humble and honest recognition of the limited power of film-makers and their products. However, I feel that in this recognition there also lies a sense of hope. If relational empathy is deemed to be desirable and ethical in intercultural communication, then the three screenings were in themselves an important part of the process of creating a third culture. Any process of mutual understanding must be an ongoing one. Documentary film-making, when viewed as a process made up of human relations, does not end with the editing and distribution of the film. Preferably, the film text is only one - albeit tangible - evidence of the ongoing relationship between filmmaker and subject.

Based on these observations, I would argue that the three screenings, although far from ideal in the manner in which they were set up, provided a unique learning experience, one that can offer suggestions for future documentary film education work. First, if possible, an intimate first viewing, in which only the main subjects are present, would be significantly preferable. Another suggestion is to encourage student film-makers and subjects to be open about their personal motives when taking part in documentary film production. It is quite easy to adopt others' motives when both film-makers and subjects are inexperienced. Thus, as a third suggestion, it would seem to be of great importance to develop a common language to talk about documentary film. The subjects might not need to become film-makers, but it is important that they come to understand the perspective of the film-makers. As this study has argued, the documentary film, both as process and as product, might help to develop and articulate a third culture, and thus move beyond a preoccupation with self and similarity. One way to do this would be to introduce relational empathy as a conceptual tool in documentary film education. Similarity with subjects is not essential in this kind of empathy. And, if we accept that a documentary film is ultimately a product of the relationship between film-maker and subject, then we may also end up with documentaries that are both nuanced and meaningful.

Ultimately, I would argue that relational empathy is a pedagogical choice that is ethical, as it allows for consent that is truly informed. It also reduces the risk that film-makers will use themselves as a measure by which to judge others, while also reducing the risk of student film-makers giving too much space to the subjects, and thus suppressing their own points of view. In documentary film education in intercultural contexts, it is therefore essential for film students to resist the temptation to try to become the other or attempt to abandon their prejudices. Rather, they should be encouraged to take part in a process that stresses the construction of a shared understanding that is never static, and where there is no closure to be found. Film students and subjects alike should thus be encouraged to seek new meanings together.

\section{Notes on the contributor}

Jan Nåls, writer and academic, works as a lecturer in film at Arcada University of Applied Sciences in Finland, and is a scriptwriter and an author of several factual books. His latest efforts include an award-winning short film, Beware of Thin Ice (2016), 
and Borderline (2014), a fictional biography of Finnish bootlegger Algoth Niska, as well as Skenographia (2015), a book on modern set-design.

\section{References}

Aufderheide, P., Jaszi, P. and Chandra, M. (2009) Honest Truths: Documentary filmmakers on ethical challenges in their work. Washington, DC: Center for Social Media, School of Communication, American University.

Austin, D. and Moore Quinn, E. (2007) 'Introduction: Engagement, accountability and ethnography in applied practice'. Practicing Anthropology, 29 (3), 2-3.

Broome, B.J. (1991) 'Building shared meaning: Implications of a relational approach to empathy for teaching intercultural communication'. Communication Education, 40 (3), 235-49.

Casmir, F.L. and Asuncion-Lande, N.C. (1989) 'Intercultural communication revisited: Conceptualization, paradigm building, and methodological approaches'. In Anderson, J.A. (ed.) Communication Yearbook 12. Newbury Park, CA: SAGE Publications, 278-309.

Coplan, A. (2004) 'Empathic engagement with narrative fictions'. Journal of Aesthetics and Art Criticism, 62 (2), 141-52.

Coplan, A. and Goldie, P. (eds) (2011) Empathy: Philosophical and psychological perspectives. Oxford: Oxford University Press.

Currie, G. (1995) Image and Mind: Film, philosophy and cognitive science. Cambridge: Cambridge University Press.

Gaut, B. (2010) 'Empathy and identification in cinema'. Midwest Studies in Philosophy, 34 (1), 136-57.

Hyde-Clarke, N. (ed.) (2014) Documentary and Diversity: A collection of reflections: The impact of the NSSE programme on institutions and individuals, 2006-2014. Helsinki: Arcada Publications.

Katz, R.L. (1963) Empathy: Its nature and uses. London: Collier-Macmillan.

Keen, S. (2006) 'A theory of narrative empathy'. Narrative, 14 (3), 207-36.

Lassiter, L.E. and Campbell, E. (2010) 'What will we have ethnography do?'. Qualitative Inquiry, 16 (9), 757-67

Nash, K. (2009) 'Beyond the Frame: A study in observational documentary ethics'. Unpublished PhD thesis, University of New England, Armidale.

Nash, K. (2012) 'Telling stories: The narrative study of documentary ethics'. New Review of Film and Television Studies, 10 (3), 318-31.

Nichols, B. (2001) Introduction to Documentary. Bloomington: Indiana University Press.

Nocon, H., Nilsson, M. and Cole, M. (2004) 'Spiders, firesouls, and little fingers: Necessary magic in university-community collaboration'. Anthropology and Education Quarterly, 35 (3), 368-85.

Ruby, J. (2005) 'The ethics of image making; or, "They're going to put me in the movies. They're going to make a big star out of me..."'. In Rosenthal, A. and Corner, J. (eds) New Challenges for Documentary. 2nd ed. Manchester: Manchester University Press, 209-19.

Sanders, W. (2013) 'Documentary ethics in contemporary practices: Alternative participation, alternative ethics?'. In Suárez Villegas, J.C., Zurbano-Berenguer, B. and Saadi Haddach, O. (eds) (2013) II International Conference on Media Ethics. Proceedings of a conference held at the University of Seville, 3-5 April 2013. Online. https://idus.us.es/xmlui/bitstream/ handle/11441/42114/Pages\%20from\%20conference_proceeding_international_conference_on_ media_ethics-14.pdf?sequence=1\&isAllowed=y (accessed 25 May 2018).

Shohat, E. and Stam, R. (1994) Unthinking Eurocentrism: Multiculturalism and the media. London: Routledge.

Stein, E. (1989) On the Problem of Empathy: The collected works of Edith Stein. 3rd rev. ed. Washington, DC: ICS Publications.

Tan, E.S. (2011) Emotion and the Structure of Narrative Film: Film as an emotion machine. London: Routledge.

Thomson-Jones, K. (2008) Aesthetics and Film. London: Continuum.

Vaage, M.B. (2010) 'Fiction film and the varieties of empathic engagement'. Midwest Studies in Philosophy, 34 (1), 158-79.

Winston, B. (1995) Claiming the Real: Documentary film revisited. London: BFI Publishing. 